\title{
Insulin Initiation: An Uttar Pradesh Perspective
}

\author{
Nitin Gupta ${ }^{1}$
}

${ }^{1}$ Department of Medicine, Harsh Multispeciality Hospital, Muzaffarnagar, Uttar Pradesh, India

\begin{abstract}
Address for correspondence Nitin Gupta, MD, Department of Medicine, Harsh Multispeciality Hospital, Muzaffarnagar, Uttar Pradesh, India (e-mail: docnitin7@gmail.com).
\end{abstract}

J Soc Health Diab 2018;6:111.

Diabetes prevalence has been rising more rapidly in middleand low-income countries. More than $10 \%$ of urban Indians have diabetes, at least half of the Indians who have it do not know it, and the prevalence of the disease is increasingly shifting to poorer people. Across the 15 states, $7.3 \%$ of people had diabetes and one-half of them had not previously been diagnosed with the condition. The prevalence of diabetes was higher in urban areas (11.2\%) than in rural areas (5.2\%). It was higher in mainland states than in the northeast. ${ }^{1}$

Muzaffarnagar is a city and a municipal board in the Indian state of Uttar Pradesh and is a part of National Capital Region. It is the headquarters of the Muzaffarnagar district. The last population estimate in 2011 was around 495,500. This was $0.04 \%$ of the total India population. ${ }^{2}$

High-carbohydrate diet is quintessential for people of Uttar Pradesh. Dishes such as puri-aloo and kachori are a necessary part of festivities, which in turn are a frequent occurrence in the state. Mutton biryanis of the state are world famous. Western part of the state forms the core of sugarcane production in the country. About two-thirds of the total sugarcane produced in India is consumed for making gur and khandsari, and hence the same are consumed a lot by the people of the state.

Diabetes management in Uttar Pradesh is plagued with various superstitions and myths, which hinder the patients from seeking medical advice and practicing healthy lifestyle. Fasting for the whole lunar month of Ramadan is considered as an obligatory duty of every healthy Muslim, but fasting in a diabetic person increases the risk for hypoglycemia, hyperglycemia, diabetic ketoacidosis, dehydration, and thrombosis. ${ }^{3}$

Consuming high amount of carbohydrates, saturated fats, and trans-fats causes increased diabetes risk in all populations, whereas risk is significantly reduced by consuming low glycemic index foods and foods high in dietary fiber. Generally, North Indian meals have higher percentage of carbohydrate, which are highly caloric. Sedentary lifestyle increases the risk of diabetes in all ethnic groups; however, South Asians appear to be even less physically active than their Caucasian counterparts. Agriculture and trade policies encourage overconsumption of unhealthy foods, whereas urban design and transport facilities promote sedentary lifestyle.

All these factors make it necessary to initiate the use of insulin early in diabetic patients of this region. However, initiating insulin has its own problems. There are several barriers for initiating insulin such as fear of self-injection, fear of needles, negative misconceptions about initiating insulin, inconvenience, and patient perception as personal failure. ${ }^{4,5}$ These barriers need to be overcome because early insulin therapy improves $\beta$-cell function while leading to a significant improvement in glycemia.

Various continuing medical education programs and workshops can be arranged to improve awareness about insulin, at the physician level. The workshops can invite physicians for open discussions about the queries they have. Various tough and complex issues of diabetes such as initiating insulin early can be addressed with examples of dayto-day life such as "while killing a snake you have to hit hard and hit early." ${ }^{\prime \prime}$ Insulin regimens and preparations should be chosen in concordance with dietary practices and preferences. The best practices followed by any physician needs to be shared and informed to their other colleagues so that they can also give benefit of those practices to their patients. Social marketing tactics ${ }^{7}$ should be used to encourage timely glycemic control in the public at large.

\section{Conflict of Interest}

None.

\section{References}

1 Anjana RM, Deepa M, Pradeepa R, et al; ICMR-INDIAB Collaborative Study Group. Prevalence of diabetes and prediabetes in 15 states of India: results from the ICMR-INDIAB population-based cross-sectional study. Lancet Diabetes Endocrinol 2017;5(8):585-596

2 Muzaffarnagar. Available at: https://muzaffarnagar.nic.in/. Accessed September 7, 2018

3 Pathan MF, Sahay RK, Zargar AH, et al. South Asian Consensus Guideline: use of insulin in diabetes during Ramadan. Indian J Endocrinol Metab 2012;16(4):499-502

4 Kalra S, Ghosal S, Shah P. Consensus on bridges for barriers to insulin therapy. J Assoc Physicians India 2017;65(3 Suppl): 23-30

5 Kalra S, Ghosal S. Barriers and bridges to insulin therapy: bio psychosocial classification. J Pak Med Assoc 2017;67(2):3, 20-321

6 Silver B, Ramaiya K, Andrew SB, et al. EADSG guidelines: insulin therapy in diabetes. Diabetes Ther 2018;9(2):449-492

7 Kalra S, Sahay R. Timely insulin use: need for social marketing. Indian J Endocrinol Metab 2016;20(5):586-589
DOI https://doi.org/ $10.1055 / \mathrm{s}-0038-1675667$ ISSN 2321-0656.
License terms

()(1) $\Theta \circledast$ 